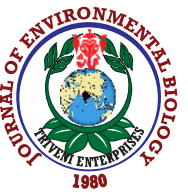

\title{
Determination of total phenolic \& flavonoids and antioxidant activity in Calligonum polygonoides $L$. from Thar Desert
}

\author{
M.K. Berwal ${ }^{*}$, S.M. Haldhar, C. Ram and P.L. Saroj \\ ICAR-Central Institute for Arid Horticulture, Bikaner-334 006, India \\ *Corresponding Author Email : mkbiochem@gmail.com
}

\section{Abstract}

Aim: The aim of the study was Identification and quantification of phenolic compounds, total flavonoides content and antioxidant potential of flower buds, foliages, bark and root of a perennial herb, Calligonum polygonoides (Phog) of Thar Desert.

Methodology: The methanolic extracts of different plant parts of C. polygonoides were subjected to LC-MS/MS (Waters Acquity UPLC-PDA, TQD) analysis for phenolic identification and spectrophotometric assay of total phenolic and flavonoids content and total antioxidant activity was estimated.

Results: A total of 15 phenolic compounds were identified and quantified, among which gallic acid content was abundant, followed by catechin. Besides these, the other major phenolic compounds detected in different plant parts were vanillic, chlorogenic acid, epicatechin, coumeric acid, catechol, vanillic acid, epicatechin and syringic acid. Extremely higher values were recorded for total phenolics, flavonoids and antioxidant capacity. The values for phenol, flavonoids and total antioxidant activity in bark extracts were higher than that of clove extract.

Interpretation: The identified phenolic compounds possess high antioxidant potential. These results provide scientific evidence for use of $C$. polygonoides as safe natural antioxidant compounds in nutraceutical and pharmaceutical industry.

Key words: Calligonum polygonoides, Nutraceuticals, Phenolics

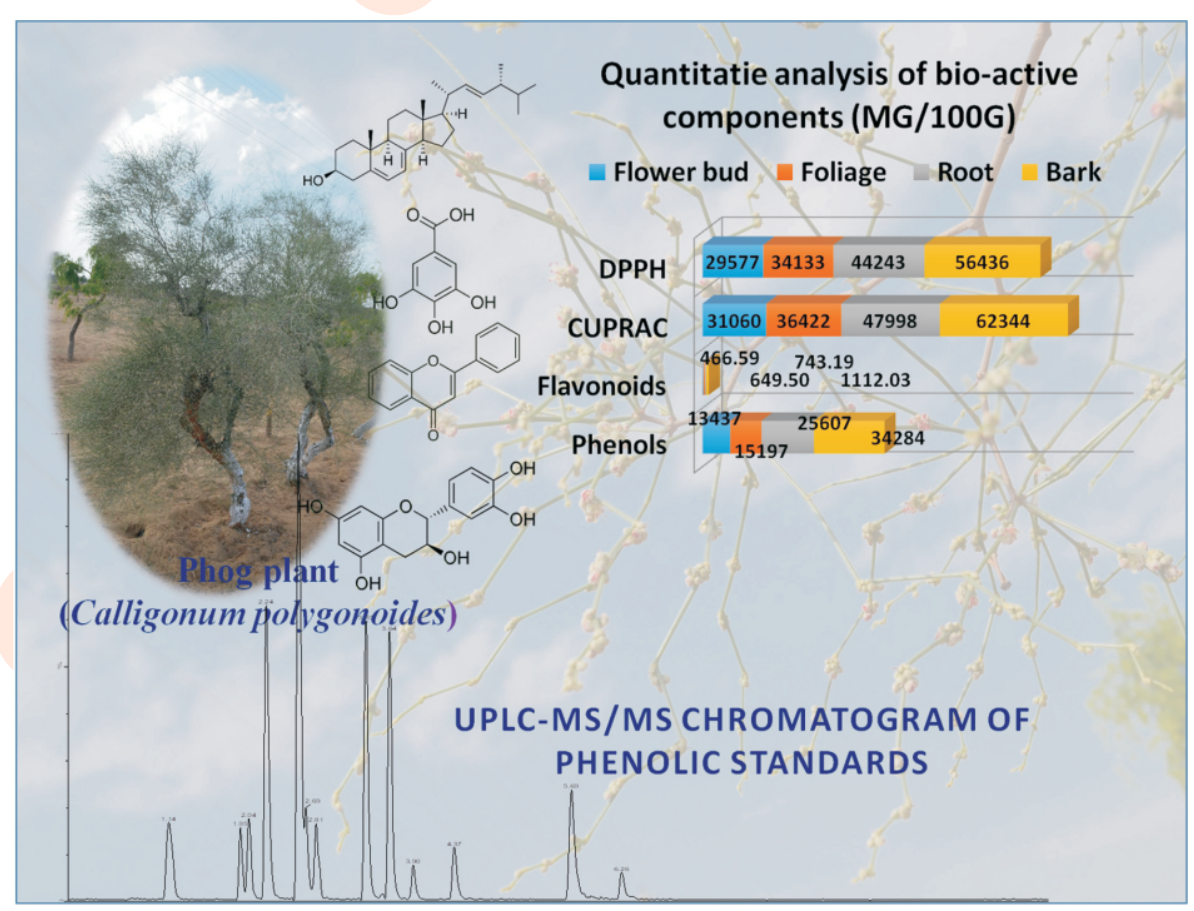

How to cite : Berwal, M.K., S.M. Haldhar, C. Ram and P.L. Saroj: Phenolic compositions, total phenolic, flavonoids and antioxidant capacity of an unexploited herb Calligonum polygonoides L. from Thar Desert. J. Environ. Biol., 42, 1347-1354 (2021). 


\section{Introduction}

Calligonum polygonoides $\mathrm{L}$. is an endemic and threatened species reported from arid zones of India, especially 'Thar Desert'. It belongs to family Polygonaceae, and is popularly known as "Phogala" "Phog" and "Phogaro" by local community (Bhandari, 1978). C. polygonoides is a small high 3-4 feet perennial shrub with articulate, whitish and fragile branches, possessing winter shedding characteristics. It is highly drought and frost resistant in its native habitat of hot arid region of the 'Thar Desert' and is dominant biomass producer of this region (Khan, 1997). It grows on longitudinal transverse and parabolic dunes and considered as the major component of plant communities of Psammophytic scrub desert (Saxena and Singh, 1976). The western part of Rajasthan is hot arid region of India. In Rajasthan, C. polygonoides is widely distributed in Barmer, Bikaner, Churu, Jaipur, Jodhpur and Jaisalmer districts of Rajasthan (Kumar et al., 2015; Shetty, 1991; Sen, 1985). C. polygonoides is a multipurpose tree as all its components possess high economic values. The abortive flower buds and succulent fruits of $C$. polygonoides are important source as food for sustenance during frequently occurring famines (Goyal and Sharma, 2008; Kumar, 2005; Bhandari, 1990). The flower buds locally called "Lasson" is generally eaten by the local communities of the desert area along with butter milk (whey) or curd during summers for cooling, which detoxifying human body by neutralizing free radicals (Kumar, 2005; Singh and Pandey, 1998). The area of naturally occurring C. polygonoides plantation is reducing drastically due to its heavy demand in charcoal production industries, overgrazing and sand mining (Tadevosyan, 2001).

Among the secondary metabolites of plants, phenolic compounds comprise one of the most abundant groups of metabolites (Acosta-Estrada, 2014). They are widely distributed as secondary metabolites derived from phenylalanine or tyrosine amino acids. The phenolic compounds have been utilized as scavenging and inhibitory agents due to their pharmaceutical and medicinal properties (Saxena et al., 2020; Ayoub et al., 2016; Zivkovic, et al., 2009). However, the most important is their antioxidant property, which detoxify human body through neutralizing free radicals, and making efficient use of nutrients (Gomes et al., 2015). Recently, various studies have been carried out for identification and quantification of phenolic compounds and total antioxidant activities in different plants (Hem et al., 2015). To study the plant based phenolic compounds, the most common techniques are extraction with organic solvents like methanol, ethanol, acetones etc., in different concentration and combinations; while for quantification and identification of phenolic compounds, spectrophotometric and chromatographic techniques are mainly used.

Traditionally, C. polygonoides has been used as therapeutic agents against many diseases and disorders viz. the paste of $C$. polygonoides acts as an antidote against snake bite, heavy dose of opium and Calotropis procera has some medicinal properties for curing typhoid, asthma, cough and cold (Mohil, 2013; Katewa and Galav, 2005). Samejo et al. (2011) reported the presence of different secondary metabolites like phenolics, flavonoids, tannin, steroids and terpenoides in different parts of phog plant and higher scavenging activity against DPPH, ABTS and superoxide along with anti-fungal and cytotoxicity against Aspergillus niger and brine shrimp, respectively. Similarly there are some reports on identification of of some flavonoids compounds in C. polygonoids flower buds (Berwal et al., 2021a; Gomes et al., 2015; Khan et al., 2015; Yawer et al., 2007). Inspite of these few studies, the reports on $\mathrm{C}$. polygonoids scavenging properties are very scanty. Even two major international phenolic databases i) Phenol-Explorer database (Perez-Jimenez et al., 2010) and ii) USDA Database for the flavonoids content of selected foods (Bhagwat et al., 2014) don't have any report on C. polygonoides. Most of the the reports in literature regarding medicinal properties of $C$. polygonoides are based on rural wisdom and Indigenous Traditional Knowledge (ITKs) only. Therefore, the present investigation was planned to give scientific authenticity to the medicianal and nutraceutical properties of $C$. polygonoides through exploring the composition and concentrations of bio-active compounds like phenolics, flavonoids and total antioxidant activity present in it.

\section{Materials and Methods}

Plant material: Flower bud, foliage, bark and root of $C$. polygonoides were collected from the research farm of ICARCentral Institute for Arid Horticulture, Bikaner (and subjected to shade drying in laboratory. Dried samples were ground and passed through 100 micron sieve for getting uniform samples. The sample powder was stored in air tight container at $-20^{\circ} \mathrm{C}$ until further use. For comparison of phenolic content, flavanoids content and total antioxidant activity, clove was used as a standard. In our preliminarily study, we recorded very high amount of peholics and TAA in its different plant parts, than surveyed the literature and found that since clove is one of the highest phenolic containing plants food in literature, it has been used as positive standard for comparing our results (PerezJimenez etal., 2010).

Methanolic extract : Sample powder of different plant parts of $C$. polygonoides weighing $250 \mathrm{mg}$ was homogenized with $20 \mathrm{ml}$ of $70 \%$ methanol using pestle and mortar. The solution was incubated at $70{ }^{\circ} \mathrm{C}$ in water bath for $1 \mathrm{hr}$. and then subjected to centrifugation at $8000 \mathrm{rpm}$ for 10 minutes at $4^{\circ} \mathrm{C}$. The supernatant was collected. The residue was subjected to further extraction, twice, with $15 \mathrm{ml}$ of $70 \%$ methanol and centrifuge. The supernatant was pooled and final volume was made up to $50 \mathrm{ml}$ with $70 \%$ methanol and stored at $-20^{\circ} \mathrm{C}$ until further use.

Identification and quantification of phenolics using UPLC- 
MS/MS: Methanolic extract was filtered and dried in vacuum concentrator without heating. The resulting residues were redissolved in $100 \mu \mathrm{l}$ of absolute methanol. Phenolic compounds were analyzed through UPLC-MS/MS as described by Xia et al. (2011). Fifteen phenolic standards (gallic acid, epigallocatechin, catechin, catechol, chlorogenic acid, caffeic acid, vanillic acid, epicatechin, syringic acid, coumaric acid, ferulic acid, salicylic acid, quercetin, cinnamic acid and kaempferol) were used in this study. Each standard (500 $\mathrm{g} \mathrm{m} \mathrm{ml}^{-1}$ of each phenolic) was dissolved in $80 \%$ methanol and separated individually. A mixture of standards was run and identified based on retention time and mass.

UPLC was performed on a Waters Acquity UPLC (Ultra Performance Liquid Chromatography) system (Waters, Milford, USA), equipped with a binary solvent delivery system with autosampler. The chromatographic separation was performed at 35 ${ }^{\circ} \mathrm{C}$ on Acquity UPLC BEH C18 (1.7 $\mu \mathrm{m}, 2.1$ x $\left.100 \mathrm{~mm}\right)$ analytical column. The elution gradient consisted of mobile phase (A) methanol and mobile phase (B) $1 \%$ acetic acid in water. The gradient program with the following proportions of solvent $B$ was applied $\mathrm{t}(\mathrm{min}), \mathrm{B} \%:(0,95),(1,80),(3,65),(5,50),(6,25),(8,25)$, $(10,50),(12,85),(14,95),(15,95)$. The solvent flow rate was maintained at $0.4 \mathrm{ml} \mathrm{min}^{-1}$ and injection volume was set as $10 \mu \mathrm{m}$.

MS detection was performed using a Waters Acquity UPLC coupled to TQ mass spectrometer (Aquity) and MS system equipped with electro spray ionization (ESI) source operated in negative ion mode and a multiple reaction monitoring (MRM) scan mode. ESI ionization conditions were set at source temperature $150^{\circ} \mathrm{C}$, negative ionization mode, source voltage " $3.2 \mathrm{kV}$. High purity nitrogen (>99.999\%) was used as curtain and auxiliary gas. The quantity of individual phenolics was calculated based on area and concentration of standards.

Total phenolics: The total phenolics in extracts were estimated following Folin-Ciocalteu method described by Medini et al. (2014). The total phenolics content of sample extracts was expressed as mg gallic acids equivalents (GAE) $100 \mathrm{~g}^{-1} \mathrm{~d}$.wt. All samples were analyzed in triplicates.

Flavonoids: Total flavonoids content in extracts was determined by the aluminum chloride colorimetric assay (Medini et al., 2014) with minor modifications. A volume of extracts (1 $\mathrm{ml})$ was mixed with $0.3 \mathrm{ml}$ each of $5 \% \mathrm{NaNO}_{2}$ and $10 \% \mathrm{AlCl}_{3}$ and $3.4 \mathrm{ml}$ of $1 \mathrm{M}$ $\mathrm{NaOH}$. The mixtures were incubated for $15 \mathrm{~min}$ at room temperature and measured the $O D$ at $510 \mathrm{~nm}$ against the reagent blank. The total flavonoids content was expressed as $\mathrm{mg}$ catechole equivalent (Ct. E) $100 \mathrm{~g}^{-1}$ d.wt. The complete flavonoids assay was carried out in three replications.

Total antioxidant activity by CUPRAC assay: The reducing capacity of the extracts was assayed by CUPRAC methods described by Apak et al. (2004) with some modifications. In this assay, $1 \mathrm{ml}$ each of cupric chloride ( $10 \mathrm{mM})$, ethanolic neocuproin (75 mM) and ammonium acetate (1 $\mathrm{M}, \mathrm{pH} 7.0)$ mixed simultaneously in a test tube containing $2 \mathrm{ml}$ of distilled water followed by $100 \mu \mathrm{l}$ methanolic extract. These mixtures were incubated in dark for $30 \mathrm{~min}$ at room temperature and the $\mathrm{OD}$ was read at $450 \mathrm{~nm}$ against the reagent blank. Ascorbic acid was used as positive reference standard and expressed in mg AAE $100 \mathrm{~g}^{-1}$. The TAA as CUPRAC assays were replicated thrice to get mean values.

Total antioxidant activity by DPPH assay: The radical scavenging activity was assayed by DPPH method described by Re et.al. (1999) with some modifications. Accordingly, $100 \mu \mathrm{l}$ methanolic extract was taken in test tubes and the volume was make up with $500 \mu \mathrm{l}$ of distilled water followed addition of $0.006 \%$ DPPH solution. The tubes were incubated under dark for $5 \mathrm{~min}$ and the OD was recorded at $517 \mathrm{~nm}$. A blank set was also run simultaneously with distilled water. Ascorbic acid was used as positive reference standard and the results were expressed in $\mathrm{mg}$ AAE $100 \mathrm{~g}^{-1}$. The TAA by DPPH assay was carried out in five replications.

Statistical analysis: The direction and magnitude of correlation between variables was performed using analysis of variance (ANOVA) and $p$ values $<0.05$ were regarded as significant. The assays were carried out in triplicate and the results were standardized and expressed as mean values. To assess the relationship between the activities of two different assays, Pearson's correlation coefficients $(R)$ were calculated to determine their relationship.

\section{Results and Discussion}

Plant extracts have been extensively used to treat numerous diseases since centuries. The mode of action of these plant extracts is based on the presence of phenolic compounds (Sehitoglu et al., 2015; Khoddami et al., 2015). Phenolics are major phyto-chemical group widely occurring in plants having considerable physiological and morphological importance for plants with strong antioxidant potential. Several studies have been correlated with the antioxidant, anti-inflammatory, anticancer and antimicrobial activities of many plants species with their phenolic content (Kim et al., 2016; Oueslati et al., 2012). Thus, identification and quantification of phenolic compounds from different plant sources is becoming ever more important due to their potential application in pharmaceutical, nutraceutical and functional food industries.

In the UPLC-MS/MS chromatogram (Fig. 1), peak 1 exhibited a negative molecular ions at [MS-H] ${ }^{+}$at $\mathrm{m} / \mathrm{z}$ of 168.91 and 124.82 for parent and daughter ions at RT of $1.18 \mathrm{~min}$, respectively, which corresponded to gallic acid. Peak 2 had an $\mathrm{m} / \mathrm{z} 305.06$ and 124.82 at $1.99 \mathrm{RT}$, corresponding to epigallocatechin, peak 3 had an $\mathrm{m} / \mathrm{z} 289.07$ and 108.84 at RT of 


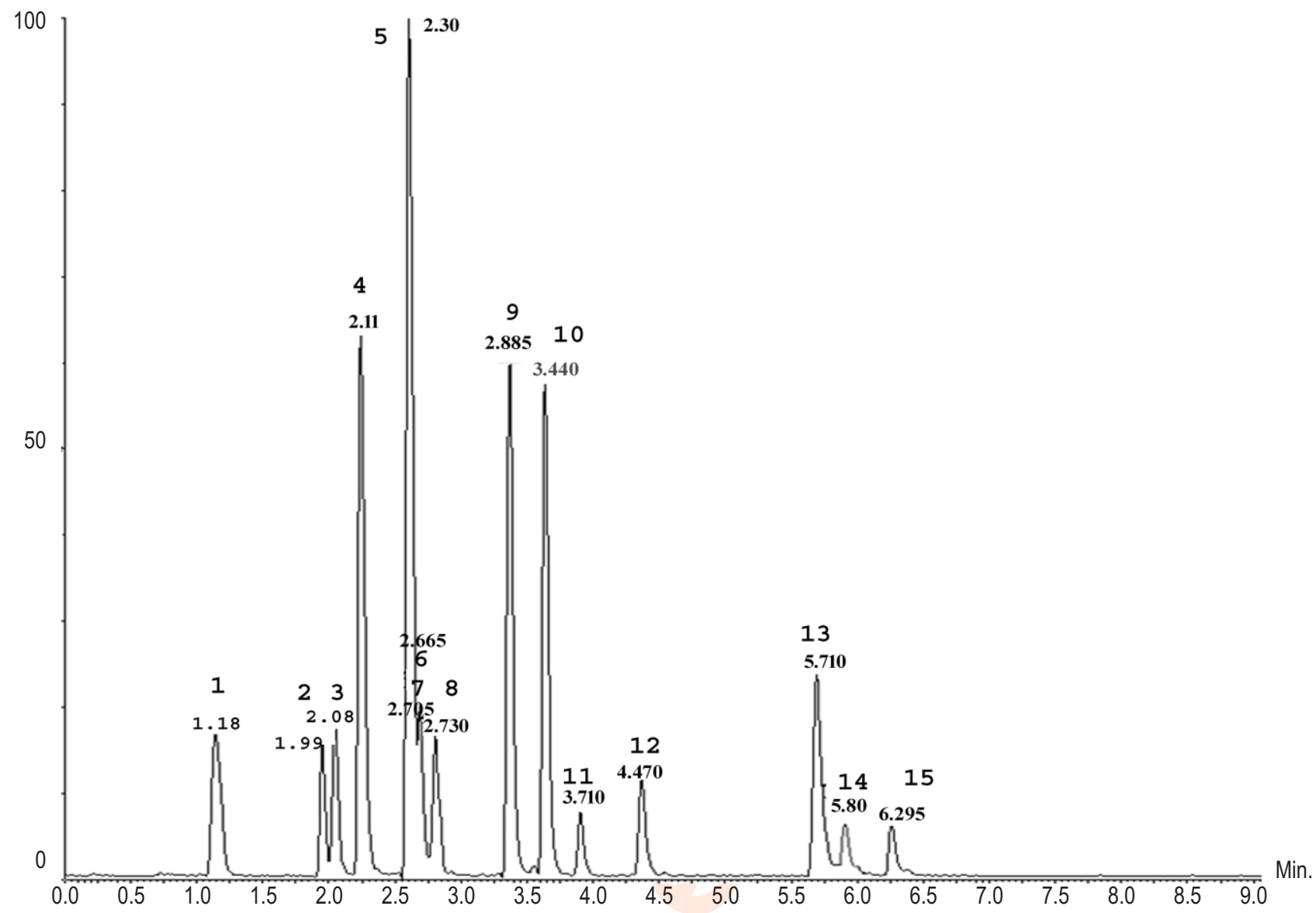

Fig. 1 : Standard chromatogram of mixture of 15 phenolic compounds (gallic acid, epigallocatechin, catechin, catechol, chlorogenic acid, caffeic acid, vanillic acid, epicatechin, syringic acid, coumaric acid, ferulic acid, salicylic acid, quercetin, cinnamic acid and kaempferol. Retention time (min.) of 1-15 compound is indicated.

$2.08 \mathrm{~min}$ which indicated catechin. Peak 4 showed an $\mathrm{m} / \mathrm{z}$ 108.89and 107.80 and were identified as catechol. Peak 5 had a negative molecular ion at an $\mathrm{m} / \mathrm{z}$ of 353.12 and 190.11 at $2.30 \mathrm{RT}$ and corresponding compound was identified as chlorogenic acid. Similarly, on the basis of negative molecular ions at different $\mathrm{m} / \mathrm{z}$ of parental ion and daughter ion on different retention time, all fifteen peaks were identified for their corresponding phenolic compounds indicated in Table 1 according to their RT. In order to quantify the identified individual phenolic compounds, relationship was established between peak area and concentration through linear regression analysis of all the standards (Table 1). The correlation coefficient $\left(r^{2}\right)$ of linearity curve between peak area and concentration was more than 0.999 for all the standards. The amount of each phenolic was expressed as $\mathrm{mg} 100 \mathrm{~g}^{-1} \mathrm{~d}$. wt. basis. Interestingly, all the fifteen phenolic acids were detected in all plant parts of $C$. polygonoides in varying concentrations (Table 1). Among identified fifteen phenolic compounds, gallic acid was the main phenolic compound in all

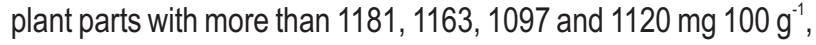
followed by catechin with $4.61,65.09,11.89$ and $172.80 \mathrm{mg} 100 \mathrm{~g}$
${ }^{1}$ in flower bud, foliage, bark and root extracts, respectively. The other phenolic acids in different plant parts showed different magnitudes. In flower buds, vanillic acid exhibited second highest content after gallic acid with $230.65 \mathrm{mg} 100 \mathrm{~g}^{-1}$, followed by catechin (4.91 mg $\left.100 \mathrm{~g}^{-1}\right)$, chlorogenic acid $\left(9.074 \mathrm{mg} 100 \mathrm{~g}^{-1}\right)$,

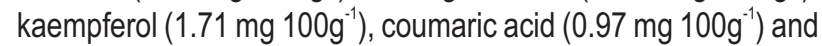
caffeic acid $\left(0.79 \mathrm{mg} 100 \mathrm{~g}^{-1}\right)$. The more abundant phenolic compounds found in foliages (after gallic acid) was epicatechin (182.10 mg $\left.100 \mathrm{~g}^{-1}\right)$ followed by catechin $\left(65.10 \mathrm{mg} 100 \mathrm{~g}^{-1}\right)$, coumaric acid (11.73 mg $\left.100 \mathrm{~g}^{-1}\right)$, catechol (5.92 mg $\left.100 \mathrm{~g}^{-1}\right)$,

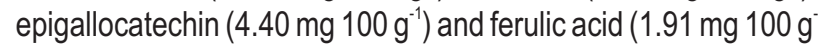
$\left.{ }^{1}\right)$. In bark and root tissues, after gallic acid and catechin, epicatechin (2.42 and $4.94 \mathrm{mg} 100 \mathrm{~g}^{-1}$ ), syringic acid (1.42 and

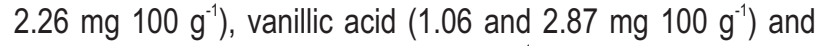

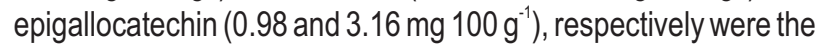
major phenolic acids present in $C$. polygonoides. The less abundant phenolics were salicylic acid, quercetin and cinnamic acid in all plant parts, while chlorogenic acid was observed in bark and root. Difference in composition and amount of phenolic content in different plant parts can be explained by the difference 
Table 1 : UPLC-MS/MS parameters of selected phenolic compounds and content in flower bud, foliage, bark and roots of phog (mg $100 \mathrm{~g}^{-1} \mathrm{~d} . \mathrm{wt}$.).

\begin{tabular}{|c|c|c|c|c|c|c|c|c|}
\hline \multirow[t]{2}{*}{ Phenolics } & \multicolumn{3}{|c|}{ MRM transition $(m / z)$} & \multirow{2}{*}{$\begin{array}{l}\text { MRM RT } \\
\text { (min) }\end{array}$} & \multirow[t]{2}{*}{ Flower } & \multirow[t]{2}{*}{ Foliages } & \multirow[t]{2}{*}{ Bark } & \multirow[t]{2}{*}{ Root } \\
\hline & $\begin{array}{l}\text { Parent } \\
\text { ion }\end{array}$ & $\begin{array}{l}\text { Daughter } \\
\text { ion }\end{array}$ & $\begin{array}{l}\text { lonization } \\
\text { mode }\end{array}$ & & & & & \\
\hline Gallic acid & 168.91 & 124.82 & Neg & 1.180 & $1181.81 \pm 10.13$ & $1163.91 \pm 14.17$ & $1097.14 \pm 12.06$ & $1120.24 \pm 8.28$ \\
\hline Epigallocatechin & 305.06 & 124.82 & Neg & 1.990 & $0.21 \pm 0.05$ & $4.40 \pm 0.08$ & $0.98 \pm 0.09$ & $3.16 \pm 0.18$ \\
\hline Catechin & 289.07 & 108.84 & Neg & 2.080 & $4.91 \pm 0.17$ & $65.09 \pm 0.07$ & $11.89 \pm 0.71$ & $172.80 \pm 5.12$ \\
\hline Catechol & 108.89 & 107.80 & Neg & 2.110 & $0.17 \pm 0.04$ & $5.92 \pm 0.03$ & $0.17 \pm 0.02$ & $0.36 \pm 0.05$ \\
\hline Chlorogenic acid & 353.12 & 190.11 & $\mathrm{Neg}$ & 2.300 & $9.07 \pm 0.73$ & $0.29 \pm 0.02$ & $0.05 \pm 0.00$ & $0.06 \pm 0.00$ \\
\hline Caffeic acid & 178.95 & 134.83 & Neg & 2.665 & $0.79 \pm 0.08$ & $1.33 \pm 0.14$ & $0.085 \pm 0.00$ & $0.09 \pm 0.00$ \\
\hline Vanillic acid & 166.95 & 107.81 & $\mathrm{Neg}$ & 2.705 & $230.65 \pm 7.05$ & $1.13 \pm 0.13$ & $1.06 \pm 0.15$ & $2.87 \pm 0.37$ \\
\hline Epicatechin & 289.08 & 122.82 & $\mathrm{Neg}$ & 2.730 & $0.35 \pm 0.01$ & $182.09 \pm 7.09$ & $2.42 \pm 0.03$ & $4.94 \pm 0.05$ \\
\hline Syringic acid & 197.00 & 122.80 & Neg & 2.885 & $0.27 \pm 0.03$ & $0.63 \pm 0.09$ & $1.423 \pm 0.07$ & $2.26 \pm 0.03$ \\
\hline Coumaric acid & 162.94 & 118.84 & Neg & 3.440 & $0.97 \pm 0.06$ & $11.73 \pm 0.35$ & $0.09 \pm 0.01$ & $0.09 \pm 0.00$ \\
\hline Ferulic acid & 192.97 & 133.85 & Neg & 3.710 & $0.35 \pm 0.02$ & $1.91 \pm 0.01$ & $0.46 \pm 0.03$ & $0.61 \pm 0.01$ \\
\hline Salicylic acid & 137.92 & 93.82 & Neg & 4.470 & $0.34 \pm 0.00$ & $0.13 \pm 0.01$ & $0.08 \pm 0.00$ & $0.11 \pm 0.00$ \\
\hline Quercetin & 301.03 & 150.81 & $\mathrm{Neg}$ & 5.710 & $0.38 \pm 0.04$ & $0.43 \pm 0.04$ & $0.21 \pm 0.00$ & $0.15 \pm 0.02$ \\
\hline Cinnamic acid & 146.93 & 76.79 & Neg & 5.800 & $0.083 \pm 0.00$ & $0.35 \pm 0.02$ & $0.05 \pm 0.01$ & $0.28 \pm 0.03$ \\
\hline Kaempferol & 285.03 & 92.81 & Neg & 6.295 & $1.71 \pm 0.21$ & $0.24 \pm 0.01$ & $0.162 \pm 0.03$ & $0.19 \pm 0.01$ \\
\hline
\end{tabular}

${ }^{*}$ MRM-Multiple reaction monitoring; Parent ion (m/z): Molecular ions of the standard compounds (mass to charge ratio); Daughter ion-Molecular ions of the daughter ion of standard compounds (mass to charge ratio); RT: retention time; Neg-Negative-ion mode. Values are mean of replicates $\pm S$.E.

in the tissue dependent bio-synthesis and accumulation of phytochemicals, physiological and morphological condition of the plant part like flower bud has a very short life span, foliages are photosynthetic tissues, bark is permanent hard tissue which has exposure to high temperature and light while roots are under underground tissues, and endogenous hormone levels (Chavan et al., 2014). According to Amoo et al. (2012), the aerial plant parts are often considered appropriate for the bio-synthesis and accumulation of phytochemicals in abundance compared to the underground parts. Tuyen et al. (2017) reported variable composition and concentration of phenolic compounds in bark, flower, inner skin, kernel and leaf extracts of Castanea crenata Sieb. Similar findings were also reported from different plant parts viz. inner skin, flower, leaf and fruits of Castanea sativa Miller (Lee et al., 2016; Barreira et al., 2008).

The total phenolic contents of the extracts, expressed as gallic acid equivalents (GAE), varied from 13437 to $34284 \mathrm{mg}$ GAE $100 \mathrm{~g}^{-1}$ in different plant parts of C. polygonoides, while clove

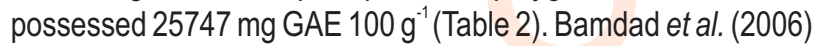
reported almost similar values for phenolic content (24391 mg GAE $100 \mathrm{~g}^{-1}$ ) in clove. Among the different plant parts, bark contained the highest phenolic content (34284 mg GAE $100 \mathrm{~g}^{-1}$ ) even higher than clove, the highest phenolic containing herbs reported till date (Perez-Jimenez et al., 2010). The flower bud, foliage and roots of C. polygonoides contained 13437, 15197 and $25607 \mathrm{mg} \mathrm{GAE} 100 \mathrm{~g}^{-1}$ phenolics, respectively. Recently, Berwal et al., (2021b) studied the seasonal changes in phenolic content of $C$. polygonoides foliages and reported as high as $8808 \mathrm{mg} \mathrm{GAE}$ $100 \mathrm{~g}^{-1}$ phenolic fresh weight basis. Phenolic content of root tissues of $C$. polygonoides was statistically at par with than that of clove $(p<0.05)$ whereas the phenolic content of flower bud and foliage was significantly lower than that of clove but was higher than that of Ceylan cinnamo (9700 mg GAE $100 \mathrm{~g}^{-1}$ ), peppermint (8052 mg GAE $100 \mathrm{~g} \mathrm{~g}^{-1}$ ), cocoa powder (5624 mg GAE $100 \mathrm{~g}^{-1}$ ) and star anise (5408 mg GAE $100 \mathrm{~g}^{-1}$ ) etc., are highest phenolic containing plants reported after clove (Perez-Jimenez et al., 2010).

The flavonoid content in different plant parts of $C$. polygonoides and clove, expressed as catechole equivalents (Ct.E) varied significantly $(p<0.05)$. Different plant parts of $C$. polygonoides namely flower bud, foliage, bark and root-contained 466.59, 649.50, 743.19 and 1112.19 mg Ct.E $100 \mathrm{~g}^{-1}$ flavonoids, respectively; while clove contained only $677.93 \mathrm{mg} \mathrm{Ct.E} 100 \mathrm{~g}^{-1}$. When surveyed the USDA database for the flavonoids content of selected foods (Bhagwat et al., 2014), it was revealed that only spices dried parsley (Petroselinum crispum) possesses higher flavonoids content with an average value of approximate $4850 \mathrm{mg}$

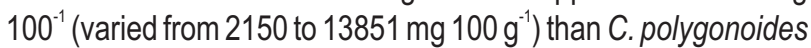
(Huber et al., 2009; Mattila et al., 2000).

Like phenolic and flavonoid contents, TAA determined by both the systems varied significantly $(p<0.05)$ among the different plant parts with the magnitude of 31060 to $62344 \mathrm{mg}$ AAE $100 \mathrm{~g}^{-1}$ (CUPRACAssay) and 29577 to $56436 \mathrm{mgAAE} 100 \mathrm{~g}$ ${ }^{1}$ (DPPH radical scavenging activity) (Table 2). Bark tissue of $C$. polygonoides possessed significantly higher TAA than that of flower buds, foliages, roots as well as clove under CUPRAC and DPPH system. Whereas, flower bud, foliages and root tissues 
Table 2 : Total phenolics, flavonoids and total antioxidant activity of different plant parts of C. polygonoides along with clove

\begin{tabular}{|c|c|c|c|c|}
\hline Treatments & $\begin{array}{l}\text { Total phenolics } \\
\text { (mg GAE } 100 \mathrm{~g}^{-1} \text { d.wt.) }\end{array}$ & $\begin{array}{l}\text { Flavonoids } \\
\text { (mg Ct.E } 100 g^{-1} \text { d.wt.) }\end{array}$ & $\begin{array}{l}\text { Total antioxidant activity } \\
\text { (CUPRAC) mg AAE } 100 \mathrm{~g}^{-1} \text { d.wt.) }\end{array}$ & $\begin{array}{l}\text { Total antioxidant activity } \\
\text { (DPPH) mg AAE } 100 g^{-1} \text { d.wt.) }\end{array}$ \\
\hline Flowerbud & $13437(115.92)^{\star \mathrm{a}}$ & $466.59(45.39)^{b}$ & $31060(176.24)^{a}$ & $29577(172.13)^{a}$ \\
\hline Foliage & $15197(123.28)^{b}$ & $649.50(50.39)^{c}$ & $36422(190.84)^{b}$ & $34133(184.89)^{b}$ \\
\hline Root & $25607(160.02)^{c}$ & $743.19(59.35)^{d}$ & $47998(219.09)^{c}$ & $44243(210.68)^{c}$ \\
\hline Bark & $34284(185.15)^{d}$ & $1112.03(73.15)^{\mathrm{e}}$ & $62344(249.69)^{e}$ & $56436(237.86)^{d}$ \\
\hline Clove & $25747(160.46)^{c}$ & $677.93(36.78)^{a}$ & $57064(238.88)^{d}$ & $33761(183.85)^{b}$ \\
\hline SEm+ & 0.84 & 0.15 & 0.57 & 0.33 \\
\hline $\operatorname{LSD}(\mathrm{P}<0.05)$ & 2.67 & 0.53 & 1.83 & 1.05 \\
\hline F calculated & 1188.10 & 7476.96 & 2942.63 & 6411.66 \\
\hline Error degree of freedom & 14 & 14 & 14 & 14 \\
\hline
\end{tabular}

*Values in parenthesis are square root transformed. Value following different letter down the column are significantly different using Turkey's HSD test ( $p$ $<0.005)$. GAE- Gallic Acid Equivalent; Ct.E-Catechole Equivalent;AAE-Ascorbic Acid Equivalent and DW-Dry weight basis

Table 3 : Pearson's correlation matrix among total phenolic, flavonoids and antioxidant potential of C. polygonoides

\begin{tabular}{lllll}
\hline & Total phenolics & Flavonoids & TAA(CUPRAC) & TAA(DPPH) \\
\hline Total phenolics & & & & \\
Flavonoids & $0.984^{*}$ & & & \\
TAA(CUPRAC) & $0.994^{* *}$ & $0.995^{* *}$ & $1.000^{* *}$ & 1.000 \\
TAA(DPPH) & $0.995^{* *}$ & $0.994^{* *}$ & \\
\hline
\end{tabular}

${ }^{* *}$ Significant at $p<0.01$ (two-tailed); ${ }^{*}$ Significant at $p<0.05$ (two-tailed)

also exhibited high TAA but was significantly lower than that of clove in CUPRAC system. The values of TAA was recorded as 31060, 36422, 47998,62344 and $57064 \mathrm{mg} \mathrm{AAE} 100 \mathrm{~g}^{-1}$ in CUPRAC system and 29547, 34133, 44243, 56436 and 33761 mg AAE $100 \mathrm{~g}^{-1}$ under DPPH radical scavenging activity, respectively, in flower bud, foliage, roots, bark and clove. A significant positive correlation was observed among total phenolic, flavonoids and TAA in different plant parts of $C$. polygonoids along with clove with a magnitude $>0.9$ correlation coefficient (Table 3).

Most of the scientific reports on medicinal properties of $C$. polygonoides are based on rural wisdom and Indigenous Traditional Knowledge (ITKs). However, clinical or in-vitro study based reports on antioxidant, anti-fungal or cyto-toxic effect of $C$. polygonoides are very scanty. Khan et al. (2015) has reported its higher antioxidant activity on DPPH \& ABTS scale along with antifungal acticity against Aspergillus niger and cyto-toxicity against brine shrimps. Few reports are available on phenolics and flavonoids content of $C$. polygonoides including a report on identification of some specific flavonoids by HPLC-EC (Gomes et al., 2015 ). In this investigation we compared the phenolics, flavonoids and total antioxidant activity of $C$. polygonoides with clove as control, which ranked first in phenolic content and total antioxidant activity. The results of phenolic content of clove (highest phenolic containing plant food reported till date) in our study were completely resembling with previous reports (Perez-
Jimenez et al., 2010). The phenolic content of bark and root tissues of $C$. polygonoides is higher than that of some medicinal plants like red clover, Catharanthus roseus and Marrubium peregrinum, which posses abou 4688, 18280 and $8978 \mathrm{mg} \mathrm{GAE}$ $100 \mathrm{~g}^{-1}$ phenolics (Nisar et al., 2017). The flavonoid content was higher in roots and bark while lower in flower bud and foliage than red clover (2661 mg $100 \mathrm{~g}^{-1}$ ) (Esmaeili et al., 2015). High values for bio-active compounds possessed by phog plant might be due to its resource poor habitat in The Thar Desert which includes high and low temperature, extremly resource poor soil, soil salinity and a prolonged drought period. A recent report of Lam et al. (2020) support this hypothese, they found that higher root zone temperature $\left(28^{\circ} \mathrm{C}\right)$ drastically improved the accumulation of bioactive compounds in Agastache rugosa. Correlation analysis for phenolics, flavonoids and total antioxidant activity of different plant parts of $C$. polygonoides exhibited linear positive association among them $(r=>0.900)$ (Table 3). Erkan et al. (2016) also reported a close positive correlation between radical scavenging activity and total phenolic content of extract from various natural sources. like Rosmarinus officinalis L. and Nigella sativa L. extracts. Similarly, a strong positive association among phenolics, flavonoids and total antioxidant activity was reported in Trifolium pratense (red clover) by Esmaeili et al. (2015).

The results herein indicate that flower bud, foliage, bark and root extracts showed potential antioxidant activity along with one of the richest source of phenolic compounds. The beauty of 
this plant is that it produces ample biomass and bioactive compounds under extreme resources poor conditions. There is indeed an urgent need to make available new plant-derived bioactive compounds; thus, these results scientifically authenticate the use of $C$. polygonoides as a source of natural effective and safe bio-active compounds for nutraceutical and pharmaceutical industry. Therefore, by the above mentioned high valued economic utilities of $C$. polygonoides, the regeneration and conservation of this plant is urgently required in 'Thar Desert'.

\section{Acknowledgments}

The authors thank Dr. Rakesh Bhargava, Principal Scientist, Retired Plant Physiology for editing the MS and Mr. R. Gora for helping in sample collection and extract preparation. We also thank the Indian Council of Agricultural Research, New Delhi for all financial support as in-house project.

\section{Add-on Information}

Author's contribution : M. K Berwal: Conceived, conceptualized, Investigations and writing of original draft; S. M. Haldhar: Sample preparations and investigations; C. Ram: statistical analysis and editing; P.L. Saroj: Reviewed and critically analyzed the manuscript.

Research content : The research content of manuscript is original and has not been published elsewhere.

\section{Ethical approval : NotApplicable}

Conflict of interest: The authors declare that there is no conflict of interest.

\section{Data from other sources : NotApplicable}

Consent to publish : All authors agree to publish the paper in Journal of Environmental Biology.

\section{References}

Acosta-Estrada, B.A., J.A. Gutierrez-uribe and S.O. Serna-Saldivar: Bound phenolics in foods: A review. Food Chem., 152, 46-55 (2014).

Amoo, S.O., A.O. Aremu and J.V. Staden: In-vitro plant regeneration, secondary metabolite production and antioxidant activity of micropropagated Aloe arborescens Mill. Plant Cell, Tissue Organ Culture, 111, 345-358 (2012).

Apak, R., K. Guçlu, M. Ozyurek and S.E. Karademir: Novel total antioxidant capacity index for dietary polyphenols and vitamins $C$ and $\mathrm{E}$, using their cupric ion reducing capability in the presence of neocuproine: CUPRAC method. J. Agric. Food Chem., 52, 79707981 (2004).

Ayoub, M., A.C. de-Camargo and S. Fereidoon: Antioxidants and bioactivities of free, esteriûed and insoluble-bound phenolics from berry seed meals. Food Chem., 197, 221-232 (2016).

Bamdad, F., M. Kadivar and J. Keramat: Evaluation of phenolic content and antioxidant activity of Iranian caraway in comparison with clove and BHT using model systems and vegetable oil. Int. J. Food Sci. Technol., 41(S1), 20-27 (2006).

Barreira, J.C.M., I.C.F.R. Ferreira, M.B.P.P. Oliveira and J.A. Pereira: Antioxidant activities of the extracts from chestnut flower, leaf, skins and fruit. Food Chem., 107, 1106-1113 (2008).

Berwal, M.K., S.M. Haldhar, C. Ram, J.S. Gora, D. Singh and D.K. Samadia: GC-MS/MS based phytochemical screening of therapeutic potential of Calligonum polygonoides $\mathrm{L}$. flower bud against chronic diseases. Pharmacog Mag., 17, 68-76 (2021a).

Berwal, M.K., S.M. Haldhar, C. Ram, S. Shil, R. Kumar, J.S. Gora, D. Singh, D.K. Samadia, M. Kumar, and M. Mekhemar: Calligonum polygonoides $L$. as novel source of bioactive compounds in hot arid regions: Evaluation of phytochemical composition and antioxidant activity. Plants, 10, 1156 (2021b).

Bhagwat, S., D.B. Haytowitz, and J.M. Holden: USDA Database for the flavonoid content of selected foods-3.1. Nutrient Data Laboratory, Beltsville Human Nutrition Research Center, Agricultural Research Service U.S. Department of Agriculture. database, pp. 173 (2014). http://www.ars.usda.gov/nutrientdata.

Bhandari, M.M.: Flora of the Indian Desert. Scientific Publishers, Jodhpur, pp. 331-332 (1978).

Bhandari, M.M.: Flora of the Indian Desert. MPS Repros, Jodhpur, India, (1990).

Chavan, J.J., N.B. Gaikwad, S.D. Umdale, P.R. Kshirsagar, K.V. Bhat and S.R. Yadav: Efficiency of direct and indirect shoot organogenesis, molecular profiling, secondary metabolite production and antioxidant activity of micropropagated Ceropegia santapaui. Plant Growth Regul., 72, 1-15 (2014).

Erkan, N., G. Ayranci and E. Ayranci: Antioxidant activities of rosemary (Rosmarinus officinalis L.) extract, blackseed (Nigella sativa L.) essential oil, carnosic acid, rosmarinic acid and sesamol. Food Chem., 110, 76-82 (2016).

Esmaeili, A.K., R.M. Taha, S. Mohajer and B. Banisalam: Antioxidant activity and total phenolic and flavonoid content of various solvent extracts from in-vivo and in-vitro grown Trifolium pratense L. (red clover). BioMed. Res. Int., 2015, 11 (2015). https://doi.org/10.1155 /2015/643285

Gomes, S.M.C., I.P.G. Fernandes, N.S. Shekhawat, S. Kumbhat and A.M. Oliveira-Brett: Calligonum polygonoides Linnaeus extract: HPLC-EC and total antioxidant capacity evaluation. Electroanalysis, 27, 293-301 (2015).

Goyal, M. and S.K. Sharma: Traditional wisdom and value addition prospects of arid foods of desert region of North-West India. Indian J. Tradit. Know., 8, 581-585 (2008).

Ham, J.S., H.Y. Kim and S.T. Lim: Antioxidant and deodorizing activities of phenolic components in chestnut inner shell extracts. Ind. Crops Prod., 73, 99-105(2015).

Huber, L.S., R. Hoffman-Ribani and D.B. Rodriguez-Amaya: Quantitative variation in Brazilian vegetable sources of flavonols and flavones. Food Chem., 113, 1278-1282 (2009).

Katewa, S.S. and P.K. Galav: Traditional herbal medicines from Shekhawati region of Rajasthan. Indian J. Tradit. Know., 4, 237245 (2005).

Khan, A., R.A. Khan, M. Ahmed and N. Mustaq: In-vitro antioxidant, antifungal and cytotoxic activity of methanolic extract of Calligonum polygonoides. Bangladesh J. Pharmacol., 10, 316320 (2015).

Khan, T.I.: Conservation of biodiversity in Western India. Environ.,17, 
283-287 (1997).

Khoddami, A., M.A. Wilkes and T.H. Roberts: Techniques for analysis of plant phenolic compounds. Molecules, 18, 2328-2375 (2015).

Kim, J.H., D.U. Ahn, J.B. Eun and S.H. Moon: Antioxidant effect of extracts from the coffee residue in raw and cooked meat. Antioxidants, 5, 21 (2016)

Kumar, M., M. Tiwari, P. Mohil, V. Bharti and U. Jain: Calligonum polygonoides Linn: An important rare shrub species in Thar Desert of India. Indian J. Plant Sci., 4, 63-66 (2015).

Kumar, S., F. Parveen and P. Narain: Medicinal Plants in Indian Arid Zone. CAZRI, Jodhpur, 64 pages (2005).

Lam, V.P., S.J. Kim, G.J. Bok, J.W. Lee and J.S. Park: The effects of root temperature on growth, physiology, and accumulation of bioactive compounds of Agastache rugosa. Agriculture, 10, 162 (2020).

Lee, N.K., B. Su, D. Som, H. Hee, J. S. Kim and H. D. Paik: The impact of antimicrobial effect of chestnut inner shell extracts against Campylobacter jejuni in chicken meat. LW Food Sci. Technol., 65, 746-750 (2016).

Mattila, P.J. Astola and J. Kumpulainen: Determination of flavonoids in plant material by HPLC with diode-array and electroarray detection. J. Agric. Food Chem., 48, 5834-5841 (2000).

Medini, F., H. Fellah, R. Ksouri and C. Abdelly: Total phenolic, flavonoid and tannin contents and antioxidant and antimicrobial activities of organic extracts of shoots of the plant Limonium delicatulum. J. Taibah Uni. Sci., 8, 216-224 (2014).

Mohil, P.: Depleting diversity of Calligonum polygonoides L. with their importance in the arid region of India. Environmental Conscious. Human Percep., pp. 90-96 (2013).

Nisar, A., A.S. Mamat, M.I. Hatim, M.S. Aslam and M.S. Ahmad: Antioxidant and total phenolic content of Catharanthus roseus using deep eutectic solvent. Recent Adv. Biol. Medi., 3, 7-10 (2017).

Oueslati, S., R. Ksouri, H. Falleh, A. Pichette, C. Abdelly and J. Legault: Phenolic content, antioxidant, anti-inflammatory and anticancer activities of the edible halophyte Suaeda fruticosa Forssk. Food Chem., 132, 943-947 (2012).

Perez-Jimenez, J.V. Neveu, F. Vos and A. Scalbert: Identification of the 100 richest dietary sources of polyphenols: An application of the phenol-explorer database. Euro. J. Clin. Nutri., 64, S112-S120 (2010).

Re, R., N. Pelledrini, A. Proteggente, A. Pannala, M. Yang and C. RiceEvans: Antioxidant activity applying an improved ABTS radical cation decolorization assay. Free Radi. Biol. Med., 26, 1231-1237 (1999).

Samejo, M.Q., S. Memon, M.I. Bhanger and K.M. Khan: Preliminary phytochemical screening of Calligonum polygonoides Linn. J. Pharma. Res., 4, 4402-4403 (2011).

Saxena, A., A.K. Mukhopadhyay and S.P. Nandi: Antibacterial activity of selected plants extract against pathogenic bacteria and detection of phytochemicals. J. Environ. Biol., 41, 1486-1492 (2020).

Saxena, S.K. and S. Singh: Some observations of the sand dunes and vegetation of Bikaner district in Western Rajasthan. Annal. Arid Zone, 15, 313-322 (1976).

Sehitoglu, M.H., H. Han, P. Kalin, I. Gulçin, A. Ozkan and H.Y. AboulEnein: Pistachio (Pistacia vera L.) Gum: A potent inhibitor of reactive oxygen species. J. Enzyme Inhibit. Med. Chem., 30, 264-269 (2015).

Sen, D.N.: The distribution of Calligonum polygonoides in Western Rajasthan, India a phytogeographical appraisal. J. Arid Environ., 8,121-132 (1985).

Shetty, B.V. and V. Singh: Flora of India Series 2, Flora of Rajasthan. Bot. Surv. India., 2, 744-755 (1991).

Singh, V. and R.R. Pandey: Ethenobotany of Rajasthan. Scientific Publishers, Jodhpur, India (1998).

Tadevosyan, T.L.: On the ecology of the joint weed-like Calligonum (Calligonum polygonoides L., Dicotyledones, Polygonaceae). Proceedings of Republican Youth Scientific Conference "The Future of Ecological Science in Armenia", Yerevan, Gitutiun (In Russian), pp. 35-42 (2001).

Tuyen, P.T., T.D. Xuan, D.T. Khang, A. Ahmad, N.V. Quan, T.T.T.Anh, L.H. Anh and T.N. Minh: Phenolic compositions and antioxidant properties in bark, flower, inner skin, kernel and leaf extracts of Castanea crenata Sieb. et Zucc. Antioxidant, 6, 31 (2017).

Xia, Z., L. Wei, X. Yong, Y. Liu, K. Wei-song, R. Xiao-dong, Y. Shuai, C. Yong-kuan and M. Ming-ming: Comparison of different cartridges of solid phase extraction for determination of polyphenols in tobacco by UPLC/MS/MS and multivariate analysis. Chem. Res. Chinese Uni., 27, 550-556 (2011).

Yawer, M.A., E. Ahmed, A. Malik, M. Ashraf, M.A. Rasool and N. Afza: New lipoxygenase inhibiting constituents from Calligonum polygonoides. Chem. Biodiver., 7, 1578-1585 (2007).

Zivkovic, J., Z. Zekovic, I. Mujic, V. Tumbas, D. Cvetkovic and I. Spasojevic: Antioxidant properties of phenolics in Castanea sativa Mill. extracts. Biotechnol., 47, 421-427 (2009). 